\title{
Natural supersaturation conditions needed for nucleation of air-clathrate hydrates in deep ice sheets
}

\author{
Tsutomu UCHIDA, ${ }^{1}$ Keita YASUDA, ${ }^{2}$ Yuya OTO,${ }^{2}$ Renkai SHEN ${ }^{2}$, Ryo OHMURA $^{2}$ \\ ${ }^{1}$ Faculty of Engineering, Hokkaido University, Sapporo, Japan \\ E-mail: t-uchida@eng.hokudai.ac.jp \\ ${ }^{2}$ Department of Mechanical Engineering, Keio University, Yokohama, Japan
}

\begin{abstract}
We apply new phase-equilibrium data of air-clathrate hydrates to the distribution of air hydrates in deep ice sheets to better understand their nucleation conditions. By comparing the depths at which the hydrates first appear to the phase-equilibrium condition, we estimated the critical size of an air-hydrate nucleus in an ice sheet to be $\sim 50 \mathrm{~nm}$. The estimated energy barrier for nucleation, based on the temperature dependence of supersaturation, is much smaller than that estimated previously for the pure ice system. Thus, the bubble surface may either act as a type of heterogeneous nucleus, or contain heterogeneous nuclei, for hydrate formation. Competition between nucleation-promotion and nucleation-inhibition factors may increase variation in nucleation rates, resulting in variation of the depth range of the bubble-hydrate transition zones.
\end{abstract}

KEYWORDS: clathrate hydrates, crystal growth, ice core

\section{INTRODUCTION}

Air inclusions in polar ice cores provide the only direct archive to reconstruct a record of ancient air composition. The Dome F (Antarctica) ice core, for example, has yielded air up to 720 ka old (Motoyama and others, 2007; GotoAzuma and others, 2008). However, the air bubbles originating from the space between snow particles in the firn become compressed with increasing depth in accordance with the increasing overburden pressure. When this pressure exceeds the temperature-dependent dissociation pressure of air-clathrate hydrate (hereafter, simply air hydrate) the air bubble transforms into air hydrate. As the air hydrate is transparent and sub-millimeter, the ice core becomes fully transparent after all air bubbles transform into air hydrates. But not all air bubbles transform into air hydrates at the same depth; rather, bubble and hydrate coexist in the bubble-hydrate transition zone (BHZ).

Air hydrate is a clathrate compound that traps air molecules (mostly nitrogen $\mathrm{N}_{2}$ and oxygen $\mathrm{O}_{2}$ ) within a cage-like water structure. Their existence in deep ice sheets was predicted by Miller (1969) and later confirmed by Shoji and Langway (1982) in Dye-3 (Greenland) ice cores. After that, air hydrates were found in every deep ice core in Greenland including Camp Century (Shoji and Langway, 1987), GRIP (Pauer and others, 1997), NGRIP (Kipfstuhl and others, 2001) and GISP2 (indirectly, Suwa and Bender, 2008). They were also found in Antarctica including cores drilled at Byrd (Shoji and Langway, 1987), Vostok (Uchida and others, 1994a), Dome Fuji (Narita and others, 1999) and EPICA-DML (Faria and others, 2009).

Within the air hydrates, the variation of the $\mathrm{O}_{2} / \mathrm{N}_{2}$ ratio correlates to the local summertime insolation (Bender, 2002; Fujita and others, 2009), meaning that the annual oscillations of this ratio can be counted to date older ice. However, when an air bubble transforms into air hydrate, fractionation of the gases occurs, which changes the $\mathrm{N}_{2} / \mathrm{O}_{2}$ ratio in the air inclusions in the $\mathrm{BHZ}$ (Ikeda and others, 1999). Below the $\mathrm{BHZ}$, the $\mathrm{N}_{2} / \mathrm{O}_{2}$ ratio becomes the same as that above the BHZ (Ikeda and others, 1999; Ikeda-Fukazawa and others, 2001 ). Once the core is put into storage, the $\mathrm{N}_{2} / \mathrm{O}_{2}$ ratio does not change, provided the storage temperature is carefully controlled (Kawamura and others, 2007), meaning that the measured fractionation of gases occurred in the $\mathrm{BHZ}$. It is therefore very important to understand the bubble-hydrate transformation processes for the ice-core analyses.

To study this transformation, we must know the precise phase-equilibrium conditions. However, owing to the high pressures and low temperatures involved, the phase diagram of air hydrate has been poorly known. But recently, Yasuda and others (2013) carefully measured the phase-equilibrium conditions of air (mixed $\mathrm{N}_{2}$ and $\mathrm{O}_{2}$ ) hydrate over a wide temperature range, finding corrections to the previous reported data (Miller, 1969; Kuhs and others, 2000; Mohammadi and Richon, 2010). Our approach here is to review the $\mathrm{BHZ}$ of each deep ice core from both Antarctica and Greenland, and use the most precise phase-equilibrium data to analyze their common and specific features. Our reanalysis of air-hydrate distribution in the Byrd ice core supports the new phase-equilibrium data. Use of this accurate supersaturation data then suggests a supersaturation for transforming air bubble to air hydrate in the natural condition.

\section{METHODS}

We examine here previously published data on the airhydrate distribution, temperature profile and age of ice in deep ice cores. Data of air-hydrate distributions are listed in Table 1. The locations and other sources are as follows: for Greenland, Dye-3 and Camp Century (Shoji and Langway, 1982; Shoji and others, 2000; Vinther and others, 2006, 2009), GRIP (Gundestrup and others, 1993; Pauer and others, 1997, 1999; Shoji and others, 2000; Vinther and others, 2006, 2009), NGRIP (Kipfstuhl and others, 2001; Vinther and others, 2006, 2009) and GISP2 (Meese and others, 1994; Gow and others, 1997; Suwa and Bender, 2008); for Antarctica, Byrd (Gow and others, 1968; Miller, 1969; Gow and Williamson, 1975; Shoji and Langway, 1987; Craig and others, 1993; Hammer and others, 1994; Shoji and others, 2000), Vostok (Uchida and others, 
Table 1. Air-hydrate distribution in various deep ice cores

\begin{tabular}{|c|c|c|c|c|c|c|}
\hline & \multirow{2}{*}{$\begin{array}{c}\text { Annual average } \\
\text { temperature } \\
\mathrm{K}\end{array}$} & \multirow{2}{*}{$\begin{array}{l}\text { Dissociation depth } \\
\text { of air hydrate } \\
\text { m }\end{array}$} & \multicolumn{2}{|c|}{ Bubble-hydrate transition zone (BHZ) } & \multirow{2}{*}{$\begin{array}{c}\text { Supersaturation } \\
\\
\%\end{array}$} & \multirow[t]{2}{*}{ Source } \\
\hline & & & $\begin{array}{c}\text { Top } \\
\mathrm{m}\end{array}$ & $\begin{array}{l}\text { Depth range } \\
\mathrm{m}\end{array}$ & & \\
\hline \multicolumn{7}{|l|}{ Greenland } \\
\hline Camp Century & 249.2 & 930 & 1099 & $>280$ & 17.7 & Shoji and Langway (1987) \\
\hline Dye-3 & 253.2 & 940 & 1092 & 408 & 15.8 & Shoji and Langway (1987) \\
\hline \multirow[t]{2}{*}{ GRIP } & 241.6 & 680 & 1022 & 478 & 49.6 & $\begin{array}{l}\text { Pauer and others }(1997,1999) ; \\
\text { Shoji and others }(2000)\end{array}$ \\
\hline & & & 900 & 700 & 31.6 & Kipfstuhl and others (2001) \\
\hline NGRIP & 241.2 & 675 & 916 & 184 & 35.1 & Kipfstuhl and others (2001) \\
\hline (NGRIP2) & & & 904 & 196 & 33.3 & Kipfstuhl and others (2001) \\
\hline GISP2 & 241.4 & 670 & 1000 & 700 & 47.2 & $\begin{array}{l}\text { Estimated from Suwa and } \\
\text { Bender (2008) }\end{array}$ \\
\hline \multicolumn{7}{|l|}{ Antarctica } \\
\hline Byrd & 245.2 & 720 & 727 & 373 & 0.0 & $\begin{array}{c}\text { Gow (1968, 1971), } \\
\text { Gow and Williamson (1975); } \\
\text { Shoji and Langway (1987) }\end{array}$ \\
\hline Vostok & 217.7 & 320 & 548 & 702 & 69.4 & $\begin{array}{l}\text { Uchida and others (1994); } \\
\text { Salamatin and others (1998) }\end{array}$ \\
\hline Dome F & 215.2 & 375 & 500 & 700 & 33.0 & $\begin{array}{l}\text { Ohno and others (2004); } \\
\text { Narita and others (1999) }\end{array}$ \\
\hline EPICA-DML & 228.6 & 492 & 700 & 525 & 42.6 & $\begin{array}{l}\text { Faria and others (2010); } \\
\text { Bendel and others (2013) }\end{array}$ \\
\hline
\end{tabular}

1994a,b; Lipenkov, 2000; Shoji and others, 2000), Dome Fuji (Narita and others, 1999; Ikeda-Fukazawa and others, 2001; Ohno and others, 2004, 2010; Kawamura and others, 2007; Uchida and others, 2011) and EPICA-DML (Wilhelms and others, 2007; Faria and others, 2009, 2010; Bendel and others, 2013). The precise depth of the top of the BHZ in each case is uncertain owing to observation difficulty: here the experimenter must find at least one $\sim 10 \mu \mathrm{m}$ diameter, transparent hydrate inclusion among larger, opaque air bubbles. Nevertheless, different studies of the same ice core give estimated depths for the top that agree within $50 \mathrm{~m}$ ( $\sim 22 \mathrm{~m}$ in the GRIP core (Pauer and others, 1999; Shoji and others, 2000), and $\sim 50 \mathrm{~m}$ in the Dome Fuji ice core (Narita and others, 1999; Ohno and others, 2004)). Thus, we consider that the uncertainty of the $\mathrm{BHZ}$ is at most $\pm 50 \mathrm{~m}$.

To determine the degree of non-equilibrium of the observed air hydrates, we must first know the equilibrium conditions. We use the recent measurements of Yasuda and others (2013) for air hydrates of air composition $\mathrm{N}_{2}: \mathrm{O}_{2}=$ $0.791: 0.209$, but because their experimental conditions are limited, we extrapolate their data to lower temperatures by fitting the empirical equation (Miller, 1969)

$$
\ln P_{i}^{\mathrm{d}}=(A+B) / T \text {. }
$$

Here $P_{i}{ }^{\mathrm{d}}$ is the dissociation pressure (MPa) of component- $i$ hydrate at temperature $T(\mathrm{~K})$, and $A$ and $B$ are constants. Using least-square fitting for their data, we obtain $A=8.711$ and $B=-1.646 \times 10^{3}\left(\mathrm{~K}^{-1}\right)$ for $\mathrm{N}_{2}$ hydrate, and $A=8.761$ and $B=-1.678 \times 10^{3}\left(\mathrm{~K}^{-1}\right)$ for air hydrate with $\mathrm{N}_{2}: \mathrm{O}_{2}=$ $0.791: 0.209$.

To compare these hydrate $P-T$ curves to the observed depth distributions in the ice core, we convert the pressure $P$ (MPa) to the depth $d(\mathrm{~m})$ using the overburden pressuredepth relation

$$
d=109.7 P+7.385
$$

which was estimated from Byrd ice core (Gow and Williamson, 1975). This relation was applied to all ice-core depth distributions in the present study. Although pore-close-off depths vary by drilling site, ranging from $64 \mathrm{~m}$ at Byrd station to $104 \mathrm{~m}$ at Dome Fuji station, this depth variation is much smaller than the depth for the top of the bubble-hydrate transformation zone $(>500 \mathrm{~m})$. To estimate the uncertainty in Eqn (2), we assume that the density difference between firn and ice is $0.2 \mathrm{~g} \mathrm{~cm}^{-3}$ in the depth range $64-104 \mathrm{~m}$. As a result, the depth uncertainty at the firn-ice transition is less than $\sim 10 \mathrm{~m}$. Therefore the depth uncertainty due to differences in pore close-off depth is much smaller than the abovementioned uncertainties of optical observations for the $\mathrm{BHZ}$ boundaries.

Another source of uncertainty is the variation in airbubble composition. At shallower depths of the $\mathrm{BHZ}$, the air composition roughly equals that of the atmosphere (Ikeda and others, 1999) and the air-hydrate $P-T$ relation applies. But, at greater depths of the $\mathrm{BHZ}$, the air bubbles become $\mathrm{N}_{2}$-rich. Therefore, the maximum deviation of depths due to this composition change would be the difference of $P_{\mathrm{N} 2}$ d and $P_{\text {air }}{ }^{d}$. At $260 \mathrm{~K}$, the highest temperature in the $\mathrm{BHZ}$, the pressure difference is $0.763 \mathrm{MPa}$ from Eqn (1), which is equivalent to a depth difference of $91 \mathrm{~m}$ from Eqn (2).

\section{RESULTS AND DISCUSSION}

We now use the phase equilibria data to analyze the $d-T$ profiles of deep ice cores. Figure 1 shows the temperature profiles of Antarctic ice and Greenland ice. The depth range between the shallowest and deepest observed air hydrates (solid and open circles) is defined as the $\mathrm{BHZ}$. This figure shows that the top of the $\mathrm{BHZ}$ always lies at greater depth than that for air-hydrate equilibrium. This result indicates that the experimental data for air-hydrate equilibrium conditions below the ice point are accurate enough for us 


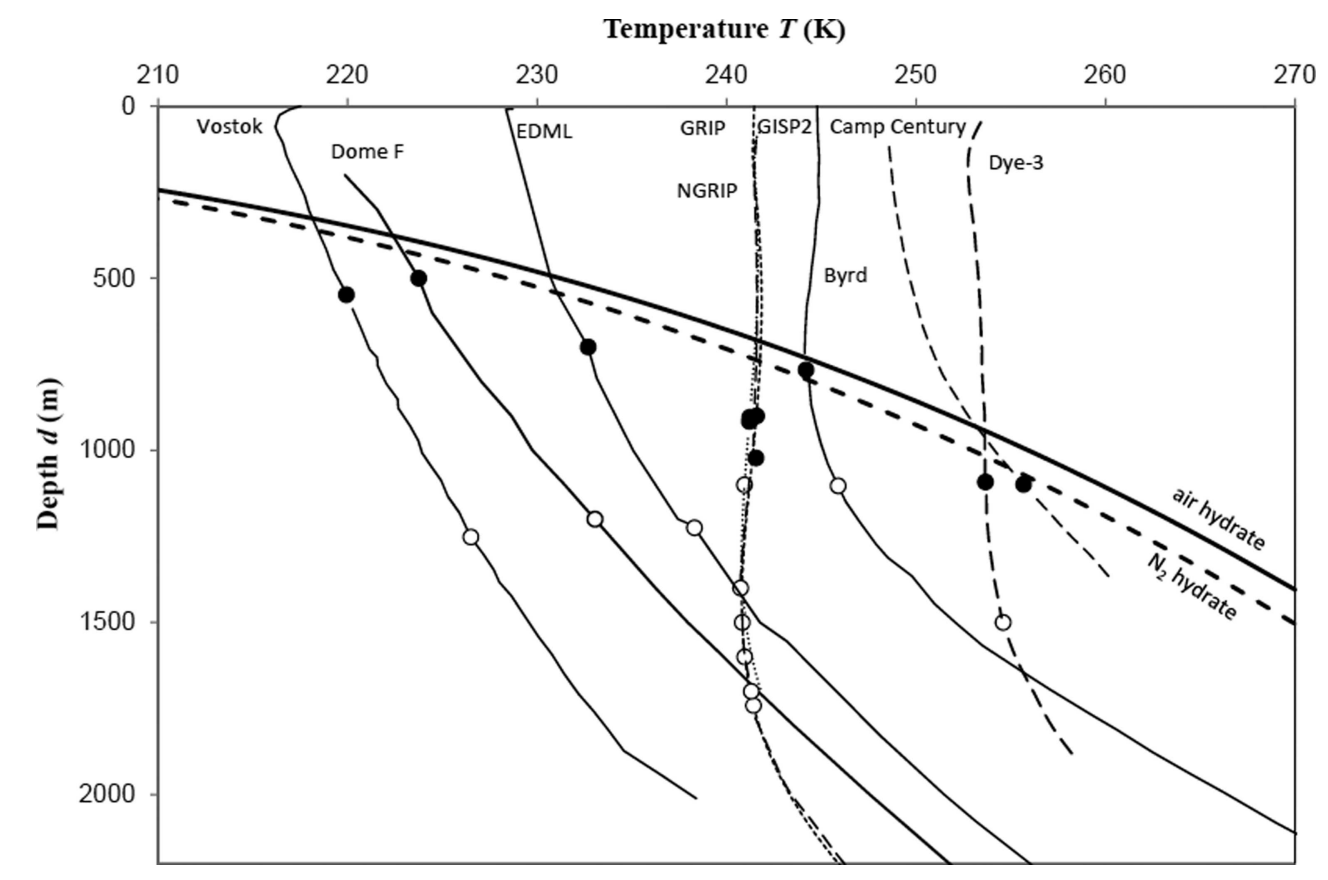

Fig. 1. Phase equilibria of $\mathrm{N}_{2}$ hydrate (thick dotted line) and air hydrate (thick solid line) compared with depth-temperature profiles of deep ice cores in Antarctica (solid lines) and Greenland (dashed lines). Dissociation pressure is converted to depth through Eqn (2). The BHZ lies between the observed shallowest depth with air-hydrate observation (solid circle) and the deepest depth with air bubbles (open circle).

to analyze the phase-transition process between air bubbles and air hydrates.

The present data may clear up an unresolved issue of the air hydrates in the Byrd ice core. Shoji and Langway (1987) and Craig and others (1993) found air hydrates $\sim 100 \mathrm{~m}$ above the equilibrium depth predicted by Miller (1969). Based on the analysis of the flowline trajectory of ice passing through the Byrd Station drill site, Craig and others (1993) considered that these air hydrates had been anomalously preserved in the ice sheet. However, using the newer equilibrium data, we find the top of the $\mathrm{BHZ}$ to be consistent with the phase-equilibrium condition. Thus the present study indicates that all air hydrates pushed up by the upstream flow dissociate when they cross the phase-equilibrium condition. This finding also confirms the accuracy of Yasuda and others' (2013) new phase-equilibrium data. Moreover, the anomalous preservation of air hydrates, when it occurs, requires temperatures below $223 \mathrm{~K}$ (Uchida and others, 1994d; Miyamoto and others, 2009). As the borehole temperature of Byrd Station is much higher, air hydrate in the Byrd ice core cannot be preserved anomalously. Thus the present result is also consistent with this temperature criterion for the anomalous preservation of air hydrates.

In the other ice cores, the top of the $\mathrm{BHZ}$ is more than $100 \mathrm{~m}$ deeper than the air-hydrate equilibrium depth. That is, the air hydrates first form at a higher-than-equilibrium pressure. Even considering the uncertainty in the $\mathrm{BHZ}$ top, this result suggests that the transformation from air bubble to air hydrate requires supersaturation. This supersaturation is likely to be intrinsic given the extremely slow rate of pressure increase. To estimate the degree of supersaturation $\sigma$, we calculate the pressure difference between $P_{\text {top, }}$ the overburden pressure at the top of the $\mathrm{BHZ}$, and $P_{\text {air }}{ }^{\mathrm{d}}$, divided by $P_{\text {air }}{ }^{\mathrm{d}}$ :

$$
\sigma=\left(P_{\text {top }}-P_{\text {air }}{ }^{\mathrm{d}}\right) / P_{\text {air }}{ }^{\mathrm{d}} \text {. }
$$

We now investigate how $\sigma$ relates to the physical parameters at the top of the $\mathrm{BHZ}$. We find that $\sigma$ correlates with temperature $T_{\text {top }}$ (Fig. 2), in which $\sigma$ is small when the ice temperature is high. This result holds for different ice cores exhibiting similar physical conditions. The driving force of air-hydrate nucleation is estimated as the chemical potential $\Delta \mu$, which for homogeneous nucleation is

$$
\Delta \mu=k T \eta \ln (1+\sigma),
$$

where $\eta=3 / 17$ is the reciprocal of the number of water molecules per cage, and $k$ is Boltzmann's constant (Hondoh, 1989). The critical radius of nucleus $r^{*}$ on the air bubble surface is

$$
r^{*}=2 v \gamma / \Lambda \mu,
$$

where $v$ is the average volume occupied by water molecule in the hydrate phase and $\gamma$ is the interfacial tension between the air-hydrate crystal and the surrounding ice matrix. At the top of the $\mathrm{BHZ}, \Delta \mu$ ranges between 20 and $80 \mathrm{~J} \mathrm{~mol}^{-1}$ between sites, which is only a small percentage of the value of $k T$. The resulting critical nucleus is $53 \pm 13 \mathrm{~nm}$, which is $\sim 30$ unit cells of the air-hydrate crystal. As the critical nucleus is very large, we consider homogeneous nucleation unlikely, meaning that nucleation must be heterogeneous.

Figure 2 also shows that one of the major controlling factors of air-hydrate nucleation is temperature. Thus, we assume that air-hydrate nucleation is a thermally activated process, and use the temperature dependence of the supersaturation to estimate the apparent activation energy for nucleation, $Q_{n}$. The absolute value of this apparent activation energy $Q_{\mathrm{n}}$ is estimated from the regression-line fit to the $\sigma$ vs $1 / T$ plot

$$
\sigma \propto \exp \left(Q_{\mathrm{n}} / k T\right)
$$

As a result, we estimated $Q_{\mathrm{n}}$ as $11.3 \pm 5.0 \mathrm{~kJ} \mathrm{~mol}^{-1}$. Although the estimation of $\sigma$ includes the uncertainty derived from the variation in the observed $\mathrm{BHZ}$ (as described in Fig. 2), the uncertainty of $Q_{n}$ is mainly due to the larger variation of $\sigma$ related to the site. In previous works 


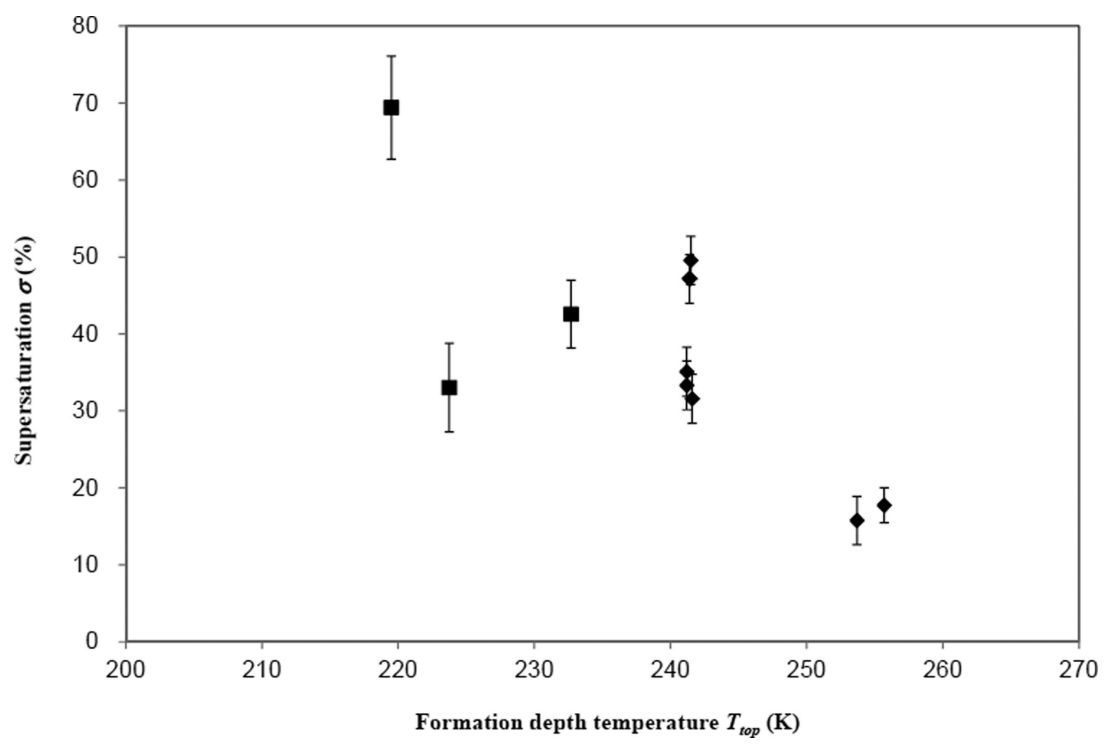

Fig. 2. Temperature $T$ dependence of the supersaturation $\sigma$ for the transformation of air bubble to air hydrate. Solid squares show $\sigma$ data in Antarctic ice, and solid diamonds show data in Greenland ice. Error bars arise from the uncertainty in the top depth of the BHZ. Note that the data in Byrd ice core are not shown because the shallowest depth is not related to the formation depth of air hydrate.

(Salamatin and others, 1999, 2001), the activation energy of air-hydrate formation was assumed to be $70 \mathrm{~kJ} \mathrm{~mol}^{-1}$, based on homogeneous nucleation theory and on an analogy with the self-diffusion of water interstitial in ice. Compared with this ideal state, the obtained apparent activation energy is only $16 \%$. This result also suggests heterogeneous nucleation on/in the air bubble.

Although the nucleation of the first air-hydrate crystals correlates with $\sigma$ and with $T$, we cannot find correlation with the depth range of the $\mathrm{BHZ}$ (the depth between the top and bottom of the $\mathrm{BHZ}$ ). For example, even ice cores with similar temperature profiles (e.g. GRIP, NGRIP and GISP2), have a range of $\mathrm{BHZ}$ that varies from 200 to $700 \mathrm{~m}$. Since the transformation from a bubble to an air hydrate completes within several days of the air-hydrate nucleation (Uchida and others, 1994c; Salamatin and others, 1998; Shimada and Hondoh, 2004), the number-density profile of air-hydrate crystals in the $\mathrm{BHZ}$ would relate to the probability of air-hydrate nucleation on air bubbles. This is based on the assumption that the transformation of bubble to hydrate occurs individually and does not propagate catalytically. The existence of a bubble-free band in the BHZ (Faria and others, 2010; Bendel and others, 2013) supports this assumption. The number-density profile of airhydrate crystals in the $\mathrm{BHZ}$ fits to the cumulative normal distribution curve (Uchida and others, 1994b; Narita and others, 1999; Ohno and others, 2004; Pauer and others, 1999; Kipfstuhl and others, 2001), which indicates that the nucleation probability is normally distributed. Therefore, the bubble-hydrate transformation occurs mainly in the middle depth of the $\mathrm{BHZ}$. The depth range of the $\mathrm{BHZ}$ is, in contrast, related to the difficulty of air-hydrate nucleation at that site. The large variation of the depth range of the $\mathrm{BHZ}$ in Greenland ice cores would indicate that air-hydrate nucleation in natural ice sheets depends not only on the temperature-pressure conditions, but also on the existence of site-specific heterogeneous nucleation conditions.

As a nucleation accelerator, Kuhs and others (2000) considered grain boundaries on the bubble surface. Shimada and Hondoh (2004) and Ohno and others (2004,
2010) pointed out, however, that micro-inclusions on the bubble were more effective than grain boundaries. The concentration and the distribution of chemical impurities usually differ by site, so chemical impurities may cause variations in the depth range of the $\mathrm{BHZ}$. By analogy with the memory effect of gas-hydrate formation (Sloan and Koh, 2008), other gas hydrates with lower dissociation pressures, such as $\mathrm{CO}_{2}$ and methane hydrates, may form before the air hydrate and act as nuclei. In addition, Lipenkov (2000) and Bendel and others (2013) indicated that small air bubbles preferentially transformed into air hydrates. This result suggests that the heterogeneity of air-hydrate nucleation is also affected by the wall curvature of the bubble. The existence of various inclusions on a bubble would then act as the nucleation accelerators by changing the physical and chemical conditions of the bubble-wall surface.

The existence of bubble-free bands in the $\mathrm{BHZ}$ (Faria and others, 2010; Bendel and others, 2013) strongly suggests that preferential nucleation of air hydrates occurs under high-impurity and small-bubble-size conditions. These observations conversely suggest that the effect of impurities or bubble sizes was confined to small regions (of the order of centimeters). Thus, to understand the hundreds-of-meters variation of the depth range of the $\mathrm{BHZ}$, we should also consider nucleation inhibitors.

The fractionation effect in the air-hydrate formation process is considered a nucleation inhibitor. Raman spectroscopy (Ikeda and others, 1999; Ikeda-Fukazawa and others, 2001 ) indicates that the gas composition of the remaining air bubbles in the $\mathrm{BHZ}$ becomes $\mathrm{N}_{2}$-rich compared with that above the $\mathrm{BHZ}$ owing to the fractionation effect of airhydrate formation, especially in deeper parts. As the dissociation pressure increases with increasing $\mathrm{N}_{2}$ concentration, the driving force of air-hydrate nucleation becomes smaller.

Nucleation acceleration and inhibition effects would act in different combination at each site. The resulting variation of air-hydrate nucleation probability would produce variation in the $\mathrm{BHZ}$ depth range. This variation would add to the variation from the different pressure-temperature conditions. 


\section{CONCLUSION}

New equilibrium data of air hydrates obtained by the modeled air + ice system were accurate enough to analyze the deep ice cores. Using these new equilibrium data on nitrogen and air clathrate hydrates, we found that all bubblehydrate transition zones in existing deep ice cores in Antarctica and Greenland have occurred under conditions of air-hydrate supersaturation. This supersaturation was not considered transient because the change in pressuretemperature conditions is sufficiently slow to be considered steady-state at each depth. However, the estimated supersaturation for air-hydrate nucleation was lower than that predicted by homogeneous nucleation theory. Moreover, the apparent activation energy of air-hydrate nucleation was estimated to be much smaller than that predicted previously for a pure ice system. We then concluded that heterogeneous nucleation occurs on the bubble surface, which is consistent with previous studies. Finally, by assuming that the depth range of the bubble-hydrate transition zone reflects the probability of air-hydrate nucleation, we argued that the variation of the depth range among different coring sites probably results from site-to-site variations in the nucleation acceleration and inhibition factors.

\section{ACKNOWLEDGEMENTS}

We thank A. Miyamoto (Hokkaido University), H. Ohno (Kitami Institute of Technology) and K. Kawamura (National Institute of Polar Research) for useful discussions on airhydrate observation and for the review of the $d-T$ diagram, and S. Kipfstuhl (Alfred Wegener Institute) and B.M. Vinther (University of Copenhagen) for their generous support of ice-core data. We also thank reviewers (S.H. Faria and anonymous) and J. Nelson for their kind suggestions.

\section{REFERENCES}

Bendel V and 6 others (2013) High-resolution variations in size, number and arrangement of air bubbles in the EPICA DML (Antarctica) ice core. J. Glaciol., 59(217), 972-980 (doi: 10.3189/2013JoG12J245)

Bender ML (2002) Orbital tuning chronology for the Vostok climate record supported by trapped gas composition. Earth Planet. Sci. Lett., 204(1-2), 275-289 (doi: 10.1016/S0012-821X(02) 00980-9)

Craig H, Shoji H and Langway CC Jr (1993) Nonequilibrium air clathrate hydrates in Antarctic ice: a paleopiezometer for polar ice caps. Proc. Natl Acad. Sci. USA (PNAS), 90(23), $11416-11418$

Faria SH and 6 others (2009) The multiscale structure of the Antarctic Ice Sheet. Part I: inland ice. In Hondoh T ed. Physics of ice core records II. (Supplement Issue of Low Temperature Science 68) Hokkaido University Press, Hokkaido

Faria SH, Freitag J and Kipfstuhl S (2010) Polar ice structure and the integrity of ice-core paleoclimate records. Quat. Sci. Rev., 29(1-2), 338-351 (doi: 10.1016/j.quascirev.2009.10.016)

Fujita S, Okuyama J, Hori A and Hondoh T (2009) Metamorphism of stratified firn at Dome Fuji, Antarctica: a mechanism for local insolation modulation of gas transport conditions during bubble close off. J. Geophys. Res., 114(F3), F03023 (doi: 10.1029/ 2008JF001143)

Goto-Azuma K and Members of the Dome Fuji Ice Core Research Group (2008) Millennial-scale climate variability during the past 720,000 years recorded in the Dome Fuji ice core. Geophys. Res. Abstr., 10, EGU2008-A-02971 (doi: 1607-7962/gra/ EGU2008-A-02971)
Gow AJ and Williamson T (1975) Gas inclusions in the Antarctic ice sheet and their glaciological significance. J. Geophys. Res., 80(36), 5101-5108

Gow AJ, Ueda HT and Garfield DE (1968) Antarctic ice sheet: preliminary results of first core hole to bedrock. Science, 161(3845), 1011-1013 (doi: 10.1126/science.161.3845.1011)

Gow AJ and 6 others (1997) Physical and structural properties of the Greenland Ice Sheet Project 2 ice cores: a review. J. Geophys. Res., 102(C12), 26 559-26 575 (doi: 10.1029/97JC00165)

Gundestrup NS, Dahl-Jensen D, Johnsen SJ and Rossi A (1993) Bore-hole survey at dome GRIP 1991. Cold Reg. Sci. Technol., 21(4), 399-402 (doi: 10.1016/0165-232X(93)90015-Z)

Hammer CU, Clausen HB and Langway CC Jr (1994) Electrical conductivity method (ECM) stratigraphic dating of the Byrd Station ice core, Antarctica. Ann. Glaciol., 20, 115-120

Hondoh T (1989) Growth processes of clathrate-hydrate crystals in deep ice sheet. J. Crystallogr. Soc. Jpn, 16(2), 149-161 [in Japanese with English summary]

Ikeda T and 7 others (1999) Extreme fractionation of gases caused by formation of clathrate hydrates in Vostok Antarctic ice. Geophys. Res. Lett., 26(1), 91-94 (doi: 10.1029/1998GL900220)

Ikeda-Fukazawa T, Hondoh T, Fukumura T, Fukazawa $\mathrm{H}$ and Mae $\mathrm{S}$ (2001) Variation in $\mathrm{N}_{2} / \mathrm{O}_{2}$ ratio of occluded air in Dome Fuji Antarctic ice. J. Geophys. Res., 106(D16), 17 799-17 810 (doi: 10.1029/2000JD000104)

Kawamura K and 17 others (2007) Northern Hemisphere forcing of climatic cycles in Antarctica over the past 360,000 years. Nature, 448(7156), 912-916 (doi: 10.1038/nature06015)

Kipfstuhl S, Pauer F, Kuhs WF and Shoji H (2001) Air bubbles and clathrate hydrates in the transition zone of the NGRIP deep ice core. Geophys. Res. Lett., 28(4), 591-594 (doi: 10.1029/ 1999GL006094)

Kuhs WF, Klapproth A and Chazallon B (2000) Chemical physics of air clathrate hydrates. In Hondoh T ed. Physics of ice core records. Hokkaido University Press, Sapporo, 373-392

Lipenkov VYa (2000) Air bubbles and air-hydrate crystals in the Vostok ice core. In Hondoh T ed. Physics of ice core records. Hokkaido University Press, Sapporo, 327-358

Meese DA and 8 others (1994) The accumulation record from the GISP2 core as an indicator of climate change throughout the Holocene. Science, 266(5191), 1680-1682 (doi: 10.1126/ science.266.5191.1680)

Miller SL (1969) Clathrate hydrates of air in Antarctic ice. Science, 165(3892), 489-490 (doi: 10.1126/science.165.3892.489)

Miyamoto A, Saito T and Hondoh T (2009) Visual observation of volume relaxation under different storage temperatures in the Dome Fuji ice core, Antarctica. In Hondoh T ed. Physics of ice core records II. (Supplement Issue of Low Temperature Science 68) Hokkaido University Press, Sapporo, 73-79

Mohammadi AH and Richon D (2010) Ice-clathrate hydrate-gas phase equilibria for air, oxygen, nitrogen, carbon monoxide, methane, or ethane + water system. Ind. Eng. Chem. Res., 49(8), 3976-3979 (doi: 10.1021/ie901820u)

Motoyama $\mathrm{H}$ and Dome Fuji Ice Core Project Members (2007) A new 3035.22 $\mathrm{m}$ deep ice core at Dome Fuji, Antarctica and reconstruction of global climate and environmental change over past 720kyr. Eos, 88, Fall Meet. Suppl. [Abstr. C51A-0076]

Narita $\mathrm{H}$ and 8 others (1999) Characteristics of air bubbles and hydrates in the Dome Fuji ice core, Antarctica. Ann. Glaciol., 29, 207-210 (doi: 10.3189/172756499781821300)

Ohno H, Lipenkov VYa and Hondoh T (2004) Air bubble to clathrate hydrate transformation in polar ice sheets: a reconsideration based on the new data from Dome Fuji ice core. Geophys. Res. Lett., 31(21), L21401 (doi: 10.1029/2004GL021151)

Ohno H, Lipenkov VYa and Hondoh T (2010) Formation of air clathrate hydrates in polar ice sheets: heterogeneous nucleation induced by micro-inclusions. J. Glaciol., 56(199), 917-921 (doi: 10.3189/002214310794457317)

Pauer F, Kipfstuhl J and Kuhs WF (1997) Raman spectroscopic and statistical studies on natural clathrates from the GRIP ice 
core, and neutron diffraction studies on synthetic nitrogen clathrates. J. Geophys. Res., 102(C12), 26519-26526 (doi: 10.1029/97JC02352)

Pauer F, Kipfstuhl J, Kuhs WF and Shoji H (1999) Air clathrate crystals from the GRIP deep ice core: a number-, size- and shape-distribution study. J. Glaciol., 45(149), 22-30

Salamatin AN, Hondoh T, Uchida T and Lipenkov VYa (1998) Postnucleation conversion of an air bubble to clathrate air-hydrate crystal in ice. J. Cryst. Growth, 193(1-2), 197-218 (doi: 10.1016/S0022-0248(98)00488-6)

Salamatin AN, Lipenkov VY, Hondoh T and Ikeda T (1999) Simulated features of the air-hydrate formation process in the Antarctic ice sheet at Vostok. Ann. Glaciol., 29, 191-201 (doi: 10.3189/172756499781821571)

Salamatin AN, Lipenkov VY, Ikeda-Fukazawa T and Hondoh T (2001) Kinetics of air-hydrate nucleation in polar ice sheets. J. Cryst. Growth, 223(1-2), 285-305 (doi: 10.1016/S0022-0248 (00)01002-2)

Shimada W and Hondoh T (2004) In situ observation of the transformation from air bubbles to air clathrate hydrate crystals using a Mizuho ice core. J. Cryst. Growth, 265(1-2), 309-317 (doi: 10.1016/j.jcrysgro.2004.01.040)

Shoji $\mathrm{H}$ and Langway CC Jr (1982) Air hydrate inclusions in fresh ice core. Nature, 298(5874), 548-550 (doi: 10.1038/298548a0)

Shoji $\mathrm{H}$ and Langway CC Jr (1987) Microscopic observations of the air hydrate-bubble transformation process in glacier ice. J. Phys. [Paris], 48, Colloq. C1, 551-556 (Supplément au 3)

Shoji H, Miyamoto A, Kipfstuhl J and Langway CC Jr (2000) Microscopic observations of air hydrate inclusions in deep ice core samples. In Hondoh T ed. Physics of ice core records. Hokkaido University Press, Sapporo, 363-371

Sloan ED Jr and Koh C (2008) Clathrate hydrates of natural gases, 3rd edn. CRC Press, Boca Raton, FL

Suwa $M$ and Bender ML (2008) $\mathrm{O}_{2} / \mathrm{N}_{2}$ ratios of occluded air in the GISP2 ice core. J. Geophys. Res., 113(D11), D11119 (doi: 10.1029/2007JD009589)
Uchida T, Hondoh T, Mae S, Lipenkov VYa and Duval P (1994a) Air-hydrate crystals in deep ice-core samples from Vostok Station, Antarctica. J. Glaciol., 40(134), 79-86

Uchida T, Duval P, Lipenkov VYa, Hondoh T, Mae S and Shoji H (1994b) Brittle zone and air-hydrate formation in polar ice sheets. Mem. Natl Inst. Polar Res., Special Issue 49, 298-305

Uchida T, Hondoh T, Mae S, Duval P and Lipenkov VYa (1994c) Effects of temperature and pressure on the transformation rate from air bubbles to air-hydrate crystals in ice sheets. Ann. Glaciol., 20, 143-147

Uchida T, Hondoh T, Mae S, Shoji H and Azuma N (1994d) Optimized storage condition of deep ice core samples from the viewpoint of air-hydrate analysis. Mem. Natl Inst. Polar Res., Special Issue 49, 306-313

Uchida T, Miyamoto A, Shin'yama A and Hondoh T (2011) Crystal growth of air hydrates over $720 \mathrm{ka}$ in Dome Fuji (Antarctica) ice cores: microscopic observations of morphological changes below $2000 \mathrm{~m}$ depth. J. Glaciol., 57(206), 1017-1026 (doi: 10.3189/002214311798843296)

Vinther BM and 12 others (2006) A synchronized dating of three Greenland ice cores throughout the Holocene. J. Geophys. Res., 111(D13), D13102 (doi: 10.1029/2005JD006921)

Vinther BM and 13 others (2009) Holocene thinning of the Greenland ice sheet. Nature, 461(7262), 385-388 (doi: 10.1038/nature08355)

Wilhelms F, Sheldon SG, Hamann I and Kipfstuhl S (2007) Implications for and findings from deep ice core drillings - an example: the ultimate tensile strength of ice at high strain rates. In Kuhs WF ed. Physics and chemistry of ice. (Special Publication 311) Royal Society of Chemistry, Cambridge, 635-639

Yasuda K, Oto Y, Shen R, Uchida T and Ohmura R (2013) Phase equilibrium condition measurements in nitrogen and air clathrate hydrate forming systems at temperatures below freezing point of water. J. Chem. Thermodyn., 67, 143-147 (doi: 10.1016/j.jct.2013.07.023) 